\title{
Lessing NA eSTÉTICA DE Adorno: MÚSICA, PINTURA E A QUESTÁO DA PSEUDOMORFOSE
}

\author{
Eduardo Socha
}

\begin{abstract}
Resumo: Neste artigo, propóe-se uma confrontação entre a teoria dos signos de Gotthold E. Lessing, tal como exposta em Laocoonte ou sobre as fronteiras da pintura e da poesia (1766), e os dois ensaios de Theodor W. Adorno sobre as relaçôes entre música e pintura (de 1950 e 1965). Pretende-se, com isso, demonstrar a presença decisiva de elementos da estética clássica alemá no pensamento adorniano do pós-guerra; em particular, observa-se o modo pelo qual a teoria racionalista de Lessing atua na abordagem dialética adorniana a respeito da irredutibilidade formal dos meios artísticos e das possibilidades de sua convergência. À luz de tal confrontação, discutem-se, em um segundo momento do artigo, os temas da conferência de Adorno de 1966, $A$ arte e as artes, que, em certa medida, consubstancia a discussão dos ensaios anteriores sobre música e pintura. Assinala-se, nesse contexto, a continuidade da posição teórica de Adorno e se apresentam as diferenças entre o processo de pseudomorfose e o de imbricação (Verfransung) dos meios artísticos, segundo o filósofo.
\end{abstract}

Palavras-Chave: Lessing. Adorno. Música. Pintura. Pseudomorfose.

\section{InTroduçấo}

Adorno não dedicou um texto específico sobre o conhecido capítulo 16 de Laocoonte ou sobre as fronteiras da pintura e da poesia (1766), no qual G. E. Lessing delimitava as singularidades formais da pintura e da poesia, visando expedientes mais adequados à intensificação de seus respectivos efeitos. Uma breve, porém incisiva, referência de Adorno à classificação de Lessing surge apenas em 1965, no ensaio Sobre algumas relaçóes entre música e pintura. ${ }^{2}$ Ape-

\footnotetext{
${ }^{1}$ Professor substituto na Universidade Federal de São Carlos (UFSCar), São Carlos, SP - Brasil.

(D) https://orcid.org/0000-0003-4038-6684. E-mail: esocha@gmail.com.

Doutor em Filosofia pela USP.

2 Adorno escreveu dois ensaios sobre as relaçôes entre música e pintura, ambos publicados no após a Segunda Guerra: Sobre a relação entre pintura e música hoje (GS 18, 140-8), publicado em 1950, e Sobre as relaçóes entre música e pintura (GS 16, 628-42), publicado em 1965. Quanto às referências
}

http://dx.doi.org/10.1590/0101-3173.2019.v42n3.06.p91 
sar disso, a relevância do Laocoonte de Lessing para a compreensão de conceitos centrais da filosofia da música de Adorno, conceitos como "pseudomorfose em pintura" (Pseudomorphose an Malerei) e "espacialização do tempo musical" (Verräumlichung der Zeit), não pode ser menosprezada. Sabemos que a filosofia de Adorno não permaneceu indiferente ao fato de Lessing ter sido o primeiro teórico, na estética clássica alemã, a propor uma distinção sistemática entre as artes do tempo e as artes do espaço. É somente a partir dessa distinção, quer explicitada, quer questionada, que conceitos como pseudomorfose e espacialização podem adquirir, afinal, alguma pertinência na filosofia de Adorno.

De início, já na primeira frase do ensaio Sobre algumas relaçóes entre música e pintura (1965), Adorno sancionava como "evidente" a distinção entre artes do tempo e artes do espaço, para então reposicionar o problema da temporalidade em geral na música: "A evidência de que a música é uma arte do tempo (Zeitkunst), que se desenvolve no tempo, significa, em duplo sentido, que o tempo não é evidente para ela, que o tempo se coloca como problema." (ADORNO, Sobre algumas relaçôes entre música e pintura, GS 16, 628).

Náo se trata de uma afirmação isolada ou de ocasiáo. Enunciados semelhantes quanto à "evidência" da música como arte do tempo podem ser encontrados em momentos históricos distintos da produção adorniana, como no primeiro ensaio sobre a relação entre pintura e música (1950), no ensaio tardio sobre Stravinsky (1962) e em Teoria estética (1970). Respectivamente:

Tendências correlatas [...] possuem significados diferentes, mesmo opostos, na arte temporal da música e na arte espacial da pintura. (ADORNO, Sobre a relaçâo entre pintura e música hoje, GS 18, 142).

Como arte temporal, a música está ligada ao fato da sucessão e, portanto, é irreversível como o próprio tempo. (ADORNO, Stravinsky, um retrato dialético, GS 16, 386).

Seria vão contestar que ela [a música] é uma arte temporal; que o tempo musical, por pouco que coincida imediatamente com o tempo da experiência real, é como este irreversível. (ADORNO, Teoria estética, GS 7, 42).

A definição da música como arte temporal "evidente" perde, contudo, seu caráter de "evidência" precisamente pela ênfase com que Adorno sublinha tal característica. Em se tratando de Adorno, tal evidência provoca suspei-

de Adorno a Lessing, estas aparecem também em Notas sobre literatura (GS 11, 79; GS 11, 325) e em Teoria estética (GS 7, 131), mas seu escopo temático afasta-se da discussão sobre a "divisão das artes". 
ta. Notamos, por um lado, que a divisão entre artes do espaço e artes do tempo coloca-se, para Adorno, tanto quanto para Lessing, como "princípio inquestionável" e "invariante". A própria expressão "pseudomorfose", amplamente utilizada por Adorno, confirmaria tal princípio: quando, em Filosofia da nova música, Adorno tematiza as tendências de pseudomorfose da música em pintura ${ }^{3}$, ou seja, da falsa (pseudo) comutação da música em pintura, o horizonte argumentativo pressupóe necessariamente a verdade da separação entre os meios, isto é, a irredutibilidade de critérios estéticos ligados à arte musical que estariam em oposição àqueles das artes visuais. Assim, ao menos implicitamente, Adorno legitimava a distinção entre os meios inaugurada pelo Laocoonte, de Lessing.

Por outro lado, é verdade que não encontramos uma distinção sistemática à maneira de Lessing, na estética adorniana. Adorno sustenta, antes, a confrontação dialética das próprias categorias de tempo e espaço no interior de cada meio artístico. Assim, se o tempo institui o meio da música - como diz Adorno, no ensaio de 1965 -, sua temporalidade interna (Zeitlichkeit) é, por sua vez, o fator pelo qual ela mesma se transforma em objeto, em coisa (Gegenstand, Ding). É desse modo que, para Adorno, a temporalidade na música se apresenta como "problema” a ser resolvido (ADORNO, GS 16, 628). Por meio da forma, que totaliza e articula seus momentos internos em contraposição ao fluxo do tempo empírico, a música consistiria em certa "objetivação do tempo" (Objektivation der Zeit). Se os momentos devem ser articulados internamente na obra, instalando-se em sua dimensão temporal, a forma é o que determina externamente a progressividade desses momentos, de tal sorte que tempo e espaço náo podem ser pensados separadamente na música. Nesse sentido, para Adorno, o problema do tempo musical coincide com o problema da forma musical, mediante o esquema da organização e do desdobramento interno dos eventos sonoros.

Encontramos, portanto, na reflexão de Adorno, o seguinte impasse: de um lado, a divisão entre artes do tempo e artes do espaço é considerada "evidente"; de outro, é na tensão permanente entre as categorias de tempo e espaço que a obra musical se estabelece. Sabemos que Adorno recusa toda definição substancial e não-histórica de obra e, por extensão, não aceita divisóes a priori entre os meios artísticos; se as primeiras páginas de Teoria estética questionavam o próprio direito de existência da arte, é porque, para o autor,

\footnotetext{
${ }^{3}$ Ver a seção "Pseudomorfose em pintura" ("Pseudomorphose an Malerei") em Adorno, Filosofia da nova música, GS 12, 175.
} 
qualquer definição a priori se revela inadequada. No entanto, veremos como a recusa à abstração sistemática de gêneros e de meios artísticos não significa a recusa de um conceito dialético de arte, fundamentado na noção de material, na disponibilidade histórica de técnicas específicas a uma prática artística, a qual leva em conta a tensão entre as categorias do tempo e do espaço. Contrariando a sistematização de Lessing, podemos adiantar que, para Adorno, a tensão entre tempo e espaço é constitutiva de cada meio artístico, de modo que este não pode ser reduzido a uma essencialidade temporal ou espacial. Ocorre que uma distinção entre arte do tempo e arte do espaço também se revelará imprescindível para a formulação de um conceito dialético, negativo, de arte. Sem esse desmembramento não sistemático, Adorno não poderia sequer encaminhar sua crítica à pseudomorfose e à espacialização.

Como mencionamos acima, a breve referência de Adorno à classificação sistemática de Lessing aparece no ensaio, de 1965, Sobre algumas relaçóes entre música e pintura, no qual Adorno rejeitava o imperativo de ordenamento proveniente da estética racionalista clássica e, consequentemente, a delimitação de fronteiras entre arte temporal e arte espacial:

As fronteiras estabelecidas (Die etablierten Grenzen), que opóem a arte do espaço e a arte do tempo, derivam da necessidade de classificar, de ordenar; surgem com maior insistência [...] nos períodos da estética clássica. Esta procura quebrar a resistência das coisas distintas que se colocam contra a cultura unificada (vereinheitlichende Kultur), assim como, por outro lado, satisfaz a necessidade cultural de unificar [...]. Algo das artes individuais sempre se rebelou contra essa intenção unificadora e igualmente divisora. A razáo para isso pode ser vista claramente - como no Laocoonte de Lessing - na divisão dos critérios estéticos que devem decidir categoricamente sobre a dignidade de uma obra de arte a partir de cima, ou seja, a partir de um modo que está além de sua constituição individual. A divisão das artes era cúmplice daqueles lugares-comuns normativos que o academicismo sempre impôs às necessidades concretas artísticas. (ADORNO, Sobre algumas relaçóes entre música e pintura, GS 16, 638).

À primeira vista, Adorno parece rejeitar, portanto, qualquer divisão $a$ priori das artes. Mas notemos que, no trecho acima, a crítica de Adorno não incide propriamente na divisão entre arte espacial e arte temporal, mas no estabelecimento de fronteiras (Die etablierten Grenzen...) que visam determinar o estatuto e o valor estéticos de uma obra a partir "de cima", ou seja, a partir de abstrações conceituais indiferentes à sua configuração particular. Para Adorno, as obras individuais "rebelam-se" contra essa "intenção unificadora", resistem a 
categorizaçôes abstratas. O que Adorno critica é o procedimento classificatório que define "fronteiras", limites, algo que já estaria indiciado no próprio título do livro de Lessing - Laocoonte ou sobre as fronteiras (Grenzen) da pintura e da poesia. Apesar disso, vale reiterar que, embora Adorno não admita a prescrição normativa de fronteiras, ele preserva os polos da distinção - a música como arte temporal e pintura como arte espacial. Tal distinção encontra-se assegurada através daquilo que o filósofo considera ser o "princípio imanente puro" de cada arte: "As artes convergem apenas quando cada uma segue de maneira pura (rein) seu princípio imanente.” ${ }^{\sharp}$ A divisão adorniana não se realiza então de forma prescritiva (visando a determinar "de cima" a dignidade de uma obra, como faz Lessing), senão de maneira funcional e descritiva, para o propósito da crítica. A fim de observarmos em que medida o pensamento adorniano consente e também abnega a divisão racionalista entre artes do espaço e artes do tempo, convém expor resumidamente a divisão sistemática fundamental do livro de Lessing.

\section{A TEORIA DOS SIGNOS E AS FRONTEIRAS DA PINTURA E DA POESIA}

Um dos objetivos de Laocoonte, de Lessing, consiste em fornecer critérios autônomos, racionais, independentes de propósitos teológicos ou éticos, para a avaliação dos meios artísticos, quando reduzidos a seus "primeiros fundamentos" (ersten Gründen): o espacial-simultâneo e o temporal-sucessivo. Embora Lessing não tenha sido o primeiro a fazer essa distinção, sua originalidade está no tratamento sistemático da questão do espaço e do tempo nos meios artísticos, no caso do livro, poesia e pintura. ${ }^{5}$ Com isso, inaugurava um novo campo reflexivo sobre as modalidades de interação dos meios artísticos, por onde se moveu a estética alemã posterior. Ao modificar a própria noção de gênero e a noção de forma estética, Lessing seria, nas palavras de Tzvetan Todorov, "o verdadeiro fundador da estética moderna.” (TODOROV, 1980, p. 34). Com efeito, em Laocoonte, Lessing (1998, p. 49) pretendia esclarecer as condiçóes formais específicas de cada meio artístico, a fim de evitar "influências perniciosas” que uma separação

\footnotetext{
${ }^{4}$ Adorno, Sobre algumas relaçöes entre música e pintura, GS 16, 629: "Die Künste konvergieren nur, wo jede ihr immanentes Prinzip rein verfolgt".

${ }^{5}$ Para Todorov, "a originalidade de Lessing está em voltar das regras empíricas a um princípio abstrato e apenas as regras que daí se pode deduzir devem ser retidas." (TODOROV, 1980, p. 36). Todorov considera que a principal contribuição de Lessing à estética estaria na ideia de endogênese das obras, isto é, na ideia de que "a presença ou a ausência de um elemento na obra é determinada pelas leis da arte que se pratica” (TODOROV, 1980, p. 30).
} 
imprecisa poderia ocasionar. Embora também admitisse uma definição de arte como imitação (mimesis), à semelhança da poética clássica e da doutrina do ut pictura poesis, a crítica de Lessing tinha como alvo principal essa mesma doutrina. ${ }^{6}$ Em Laooconte, o autor procurava determinar os limites da imitaçáo dos meios. Para tanto, indicava as regras que todo artista deveria seguir, a fim de obter o máximo efeito em sua obra e consequentemente garantir sua força imitativa. Desse modo, definia-se o "primeiro fundamento" de cada meio artístico segundo o referente espacial-simultâneo ou temporal-sucessivo.

A princípio, nada parece tão trivial quanto a afirmação de que a poesia seria arte do tempo e a pintura, arte do espaço. Mas de onde surge a necessidade de teorizar um discernimento a rigor táo banal? Como vimos, a transposição de certos temas e objetos entre os meios da imitação artística, ou seja, a emulação de um meio sobre outro, era defendida pela doutrina horaciana da ut pictura poesis. Opondo-se a essa doutrina, Lessing procurava reduzir as linguagens artísticas a seus primeiros fundamentos, a fim de evitar tanto o "desperdício de muita imaginação a troco de nada" quanto as "invasóes" entre os domínios artísticos que o "bom gosto não aprovará nunca” (LESSING, 1998, p. 211).

Assim, se Lessing entende a pintura e a poesia como artes da cópia ou da imitação (nachahmende Künste), ele náo apela, por outro lado, à simplicidade da distinção sensorial entre olhar e ouvir. Antes, refere-se a "uma relação conveniente" (ein bequemse Verhältins) dos signos (Zeichen) com seus respectivos meios. Dessa forma, na pintura, os signos são "figuras e cores no espaço", ordenados um ao lado do outro, coextensivos (nebeneinander) e seus objetos são corpos (Körper); já na poesia, os signos são "sons articulados no tempo", seguem-se uns aos outros (aufeinanderfolgende) e seus objetos constituem açóes (Handlungen) (LESSING, 1998, p. 193). Pintura e poesia separam-se, portanto, seja por seus signos, seja por seus objetos (Gegenstände): objetos coextensivos de qualidades visíveis (corpos) inspiram uma relação conveniente para a imitação em meio coextensivo (arte espacial) e, do mesmo modo, objetos sucessivos (açóes) em meio

\footnotetext{
${ }^{6}$ A doutrina do ut pictura poesis remonta à Arte poética, de Horácio, na qual se defendia a homologia retórica entre os meios artísticos. Segundo João Adolfo Hansen, nos versos 361-365 da Arte Poética, "Horácio afirma que poesia é como pintura. Ut pictura poesis é, como se sabe, tópica de competição ou emulaçáo entre as artes [...] Evidentemente, Horácio não diz que poesia é pintura ou que pintura é poesia, mas ut, 'como', propondo na conjunção comparativa a homologia retórica dos procedimentos miméticos ordenadores dos efeitos em um e outra. Assim, o ut que as relaciona parece indicar as modalidades técnicas do verossímil e do decoro necessários em cada gênero poético em termos de invenção, disposição e elocução, para que a obra particular cumpra as três funções retóricas gerais de ensinar (docere), agradar (delectare) e persuadir (movere)." (HANSEN, 2006, p. 98).
} 
sucessivo (arte temporal). Lessing reconhece que, para serem representados, tanto os corpos dependem da dimensão temporal quanto as ações dependem da espacial. Mas tal dependência ocorre apenas "alusivamente" (andeutungsweise) e não afeta a estrita homologia entre os meios artísticos específicos, seus signos correspondentes e sua forma de recepção. Ou seja, a temporalidade de uma pintura narrativa não é fornecida pelos próprios signos da pintura, não é representada nela diretamente, mas é inferida pelo espectador, a partir do objeto estático, restrito a um momento; elementos como discursividade e narratividade seriam, pois, secundários à pintura. ${ }^{7}$ De forma similar, a espacialidade na construçáo poética, a disposição "arquitetônica" de uma memória virtual seriam antes metáforas subsidiárias que náo participam diretamente do fluxo do poema atualizado e objetivado no tempo.

A partir dessa divisão sistemática, Lessing deduz os elementos de base que pertenceriam à representação direta (à "relação conveniente") de cada meio artístico, separando-a claramente da representação indireta (acidental ou “alusiva”). É assim que, por exemplo, o poeta "deveria buscar o uso de sinédoques, e não de alegorias", valorizar "onomatopeias, tropos e figuras retóricas", por serem mais convenientes ao meio no qual os objetos, afinal, correspondem a açóes (LESSING, 1998, p. 49-50). Por isso, a poesia deveria evitar a prosa descritiva. Procurando se afastar tanto da ideia de reciprocidade entre os meios, defendida pelo ut pictura poesis, quanto do estabelecimento de uma hierarquia entre os meios, à maneira de um paragone, a separação sistemática de Lessing engendra uma espécie de cartografia dos meios artísticos, cujas fronteiras devem ser observadas pelo artista. Vale a pena enfatizar um aspecto fundamental da divisão proposta por Lessing: a divisão ocorre no plano da representação direta ou da "relação conveniente", mas se dissolve no plano da representação indireta ou alusiva (MITCHELL, 1984, p. 102). Nesse sentido, tal delimitação sistemática não impediria o "bom convívio" e a "boa influência” na vizinhança entre os meios:

Assim como dois vizinhos justos e amigos não permitem que o outro tome liberdades inconvenientes no seu domínio mais íntimo, mas decerto permitem que reine uma indulgência recíproca quanto às fronteiras mais externas que compensa de modo pacífico as pequenas invasóes nos direitos um do outro que cada um se vê obrigado a fazer rapidamente premidos

7 Como observa Todorov, para Lessing, a pintura e a escultura devem escolher o momento mais fecundo, na medida em que só podem representar um único momento da açấo. O momento mais fecundo, porém, é aquele que "deixa campo livre à imaginação"; por isso, "não é preciso, pois, escolher o momento do paroxismo (o sofrimento atroz de Laocoonte), mas o que o precede ou segue" (TODOROV, 1980, p. 27). 
pela necessidade: o mesmo se passa entre a pintura e a poesia. (LESSING, 1998, p. 211)

Lessing propõe uma teoria dos signos vinculada a essa divisão, segundo a qual o signo essencialmente ordenado um ao lado do outro (nebeneinandergeordneten) proveniente da pintura seria "natural" (natürlich) e não se coaduna com o signo ordenado um após o outro (aufeinanderfolgenden) da poesia, cuja imitação se realiza de maneira "arbitrária" (willkürlich). Pintura e poesia distinguem-se não apenas pelo meio formador (corpos e açóes) e pela dimensão de seu ordenamento (espaço e tempo), mas também pelos seus signos. Daí resulta a incompatibilidade fundamental na transposição de temas e objetos entre os meios artísticos. Segundo a teoria de Lessing, formas espaciais, cores e som formariam signos "naturais", pois estão inscritos na natureza física, enquanto a linguagem verbal formaria signos "arbitrários", independentes da natureza (LESSING, 1998) ${ }^{8}$

Essa dicotomia encaminhada pela teoria dos signos torna menos "evidente" a divisão entre artes do espaço e artes do tempo no sistema de Lessing, sobretudo quando se leva em conta o caso da música. A rigor, não se questionaria a classificação da arte musical entre os meios artísticos temporais, cujos signos estariam comprometidos com a sucessividade e a narratividade. No entanto, segundo a taxonomia de Lessing, os signos musicais não constituem inicialmente "açóes", tampouco podem ser considerados "arbitrários", já que, segundo a concepção clássica, os sons provêm diretamente da natureza, ao contrário dos signos da poesia, ancorados na linguagem verbal. Lessing não chegou a concluir seu projeto sobre Laocoonte, o qual previa mais duas partes além da publicada. Contudo, em seus fragmentos, reunidos sob o título paralipomenon 27 e indicados com a observação "Para a terceira parte", Lessing realiza uma análise comparativa entre signos poéticos e musicais, cujo estilo e linguagem se enquadrariam perfeitamente àqueles do capítulo 16 do Laocoonte (RICHTER, 1999, p. 156). De acordo com tais fragmentos, a música estaria próxima da pintura e da poesia, porque, embora utilize

\footnotetext{
${ }^{8}$ Segundo sua complexa teoria dos signos, o objetivo mais íntimo da poesia seria a transformaçáo de seus signos arbitrários em signos naturais, afastando-se, portanto, do teor alegórico, mais adequado à prosa. Ou seja, as metáforas poéticas ambicionam elevar-se a signos semelhantes aos da pintura, portadores de maior "dignidade e força", por serem naturais (SELIGMANN-SILVA, 1998, p. 51); a poesia, em resumo, deseja despertar a ideia em um instante, por meio do registro metafórico da linguagem. A discussão sobre as consequências dessa complexidade escaparia do propósito do nosso trabalho.
} 
signos ordenados e articulados no tempo, de maneira sequencial, como na poesia, tais signos não seriam arbitrários, mas sim "naturais", como os da pintura (RICHTER, 1999, p. 170). As críticas de Johann Herder e Moses Mendelssohn a Lessing - quando insistem no fato de que, não a poesia, mas a música, como movimento (Bewegung), representaria a autêntica contrapartida da pintura - seriam neutralizadas à luz dessa teoria dos signos (RICHTER, 1999, p. 156). Mendelssohn procurava estabelecer uma oposição entre signos naturais e arbitrários, não mais em relação à poesia e à pintura, como no sistema de Lessing, porém, em relação à música e à pintura:

Aquela (a música) utiliza igualmente signos naturais, mas imita apenas por meio do movimento (Bewegung). A poesia possui algumas qualidades em comum com a música e algumas em comum com a pintura. Os seus signos possuem um significado arbitrário, daí eles expressarem às vezes coisas que existem uma ao lado da outra [nebeneinander], sem com isso realizarem uma invasão no campo da pintura. (MENDELSSOHN apud SELIGMANN-SILVA, 1998, p. 200, nota 2).

Todavia, Lessing sempre manteve a convicção de que a imitação da arte musical se ligava originariamente àquela da arte poética. ${ }^{9}$ Assim, ainda que a música não trate especificamente de açóes verbais, ela pode, por meio do movimento de seus signos naturais, de fato, expressar açóes. Dito de outro modo, os campos (que hoje poderíamos denominar semióticos) da poesia e da música aproximam-se pelo traço em comum e essencial da sucessividade de seus objetos no tempo. Em que pesem as nuances fornecidas pela teoria dos signos do sistema de Lessing, as quais colocam a música a meio caminho entre pintura e poesia, interessa-nos observar a demarcação entre os meios orientados pelo referente espacial-simultâneo e aqueles orientados pelo referente temporal-sucessivo, regulamentando a especificidade dos objetos de cada arte; para Lessing, portanto, a música seria um meio de articulação de signos não arbitrários, de sons ordenados um após o outro (aufeinander) no tempo.

Segundo Rodrigo Duarte, a demarcaçáo entre artes do tempo e artes do espaço realizada por Lessing era uma resposta à crescente "contaminaçáo" das formas de um meio artístico sobre outro, no âmbito da estética clássica do século 18 , conduzindo, no limite, à subordinação formal de um meio a outro (DUARTE, 2009, p. 32). A tendência problemática de subordinação, consta-

\footnotetext{
${ }^{9}$ Cf. Richter (1999, p. 161): "Lessing [...] wrote in paralipomena 27: 'There really was a time when both poetry and music together were a single art'."
} 
tada por Clement Greenberg, em Rumo a um mais novo Laocoonte, seria a verdadeira motivação para Lessing estabelecer limites, uma vez que privilegiava mais o caráter narrativo das artes temporais do que a especificidade da pintura:

Lessing, em seu Laocoonte, escrito na década de 1760, identificou a presença de uma confusão das artes tanto prática quanto teórica. Mas viu os seus efeitos prejudiciais exclusivamente em termos de literatura, e suas opiniôes sobre artes plásticas apenas exemplificam os típicos equívocos de sua época. Ele criticou os poemas descritivos de poetas como James Thompson, vendo neles uma invasão do domínio da pintura de paisagem, mas, sobre a invasão da poesia pela pintura, tudo que conseguiu foi condenar pinturas alegóricas que requeriam uma explicação e quadros como $O$ filho pródigo, de Ticiano, que incorporam "dois pontos necessariamente separados do tempo num único e mesmo quadro". (GREENBERG apud DUARTE, 2009, p. 32).

Por outro lado, Márcio Suzuki sugere que o empenho crítico de Lessing para demarcar os limites entre os meios procederia de sua reação a uma nova leitura da tragédia antiga que, então, começava a circular no século 18 e da qual o autor de Laocoonte divergia:

Seria talvez ingênuo de nossa parte acreditar que Lessing escreve seu célebre comentário sobre a escultura do Laocoonte táo-somente pelo zelo crítico de demarcar criteriosamente os limites que separam a poesia e as artes plásticas. Penso que não se entenderá inteiramente sua argumentação se não se levar em conta o interesse dele pelo teatro. A sua insistência em estabelecer o que é próprio da literatura e o que é próprio das artes plásticas visa, entre outras coisas, muito provavelmente Winckelmann, pois Lessing se ocupa seriamente em tentar preservar o drama de uma possível contaminação das artes escultóricas, ou melhor, por aquilo que Winckelmann pensa a respeito da escultura grega. (SUZUKI, 2001, p. 37-38).

De todo modo, esse conjunto de fatores históricos e de interesses externos que presidiria a divisão "racional" e "sistemática" entre arte temporal e arte espacial é suficiente, na visão de Adorno, para constatar a ausência de neutralidade e os traços ideológicos e heterônomos, na teoria de Lessing. Tal caráter ideológico, distante da postura neutra e manifestadamente "racional" pretendida por Lessing, seria denunciado por Adorno, no ensaio de 1965, conforme a passagem citada acima. Entretanto, como veremos abaixo, parte significativa desses pressupostos forneceria a base para conceitos fundamentais do próprio pensamento musical de Adorno. 


\section{Momento transcendental? Críticas ao conceito adorniano de tempo MUSICAL}

A análise da teoria de Lessing permite-nos compreender, sob outra perspectiva, a problemática da espacialização do tempo na música e da pseudomorfose da música em pintura, tendências que, segundo Adorno, incidem sobre a mitologia wagneriana e atingem seu paroxismo na fase primitivista de Stravinsky. Vejamos, primeiramente, o quanto a concepção segundo a qual cada meio artístico possuiria um "princípio imanente puro"10 remete à delimitação inaugural de Lessing, em sua recusa à emulação entre os meios. Para Lessing, a "relação conveniente" entre objetos e meios artísticos deve ser respeitada pelo artista. Conforme Adorno, a especificidade do pures Medium da música compromete-se com o aufeinanderfolgende, com o caráter processual da sucessão, do "elemento após o outro". No ensaio tardio sobre Stravinsky, de 1962, Adorno ainda considerava que,

como arte do tempo, a música está ligada, pelo seu meio puro (pures Medium), ao fato da sucessão e portanto é irreversível como o próprio tempo. Ao iniciar, compromete-se em ir adiante, a virar algo novo, a se desenvolver. (ADORNO, Stravinsky, um retrato dialético, GS 16, 386-387).

Ou seja, Adorno estaria prescrevendo, analogamente a Lessing, uma necessária adequação entre a faticidade do sonoro - sua irreversibilidade - e o "meio puro" da música. Vale observar que é precisamente esse imperativo composicional de adequação que fundamentaria não apenas sua crítica a Wagner e Stravinsky, mas também ao jazz e à vanguarda de Darmstadt, nos anos 1950 e 1960. Podemos dizer que esta seria a principal objeção à concepção adorniana de tempo musical, levantada por vários comentadores e críticos musicais: a partir da mera adequação entre meio e seus objetos, ou de uma "relação conveniente", nos termos de Lessing, Adorno deduziria uma obrigação composicional para a formalização específica do tempo na música. $\mathrm{Ou}$ seja, com base no mero truísmo de que a música transcorre no tempo, Adorno consideraria a adequação conveniente com seu meio um invariante, um dado transcendental, a condição de possibilidade da obra.

Não foram poucos os comentadores que apontaram tal "deslize” transcendental no materialismo de Adorno. Para Richard Klein, na própria formulação adorniana dos conceitos de tempo musical e de espacialização, observa-se

${ }^{10}$ Ver nota 4, acima. 
uma passagem sub-reptícia e ilegítima entre a constatação da pura fisicalidade do som, de seu meio puro no devir, e certo compromisso com a organização de uma historicidade interna da composição (KLEIN, 2011, p. 66). Ou seja, Adorno estabeleceria uma normatividade estética - ideológica e dogmática, portanto - a partir da mera descrição do contínuo, tomando a sequência irreversível de toda realização musical como o sentido estruturalmente obrigatório da temporalidade progressiva de uma obra (KLEIN, 2011, p. 64-66).

Do mesmo modo, Carl Dahlhaus censurou certo "dogmatismo adorniano", sugerindo que sua filosofia da história aplicada às formas musicais universaliza um juízo estético específico, ligado à técnica da variação em desenvolvimento (da linhagem Beethoven-Brahms-Schoenberg), revelandose por isso, a um só tempo, politicamente decisionista e esteticamente "subjetivista". ${ }^{11}$ Os termos remetem, por sua vez, à observação de Peter Bürger, para quem a ênfase adorniana no conceito de autonomia o conduziria a um "decisionismo de avaliação" (BÜRGER, 1983, p. 132): assim como em Lessing haveria um momento ideológico na distinção sistemática entre arte temporal e arte espacial, haveria um momento ideológico na concepção de Adorno segundo a qual o meio formal puro da música, seu "princípio imanente", deve seguir o ideal utópico da variação em desenvolvimento. Seria ideológico, por conseguinte, no sentido de tanto universalizar o pensamento motívicotemático como aquele que define $o$ tempo musical quanto dissimular tal universalização (BÜRGER, 2008, p. 101). Outros comentadores interpretam essa universalizaçáo, no pensamento adorniano, como o vestígio de certa tradição austro-germânica baseada na técnica da variação em desenvolvimento, no trabalho motívico-temático, consolidado com Beethoven. A tese do "ponto cego" na filosofia da música de Adorno é partilhada por diversos autores, como Wellmer ${ }^{12}$, Chua ${ }^{13}$, Zagorski ${ }^{14}$ e Adlington. ${ }^{15}$

11 "A filosofia da história - a höhere Kritik - pode ser desmembrada em, de um lado, 'decisionismo' político e, de outro, 'subjetivismo' estético.” (DAHLHAUS, 1987, p. 14).

12 "Há uma [...] outra tradição [ligando Debussy a Stravinsky] que Adorno, marcado pela tradiçấo austro-germanica de um construtivismo dinamico e expressivo, nunca soube bem o que fazer." (WELLMER apud BOISSIÈRE, 2011, p. 142).

13 “This is in fact Adorno's insight into Stravinsky's music, but it is also Adorno's blindness, for the philosopher's Teutonic prejudice can only see." (CHUA, 2007, p. 96).

14 "Despite relevant changes, Adorno's narrow reading of an Austro-German compositional tradition is a constant that defines the standard for his engagement with postwar music." (ZAGORSKI, 2005, p. 701).

15 "Adorno frequently dismantled the subject-object antinomy in his musical criticism, siding unambiguously with the subjective qualities of music as determined by his philosophical predecessors. 
Em que pese a relevância e o alcance desses comentários, veremos que os ensaios sobre música e pintura revelam uma posição mais complexa do que a apresentada na crítica dos comentadores acima. Com efeito, nesses ensaios, Adorno reconfigura dialeticamente a terminologia do Laocoonte de Lessing, de modo que a constatação de um princípio imanente associado a cada meio não leva à determinação funcional dos limites de seus materiais.

\section{Os ensaios de Adorno sobre música e pintura}

Como mencionamos no início do artigo, Adorno publicou dois ensaios sobre música e pintura: Sobre a relação entre pintura e música hoje (GS 18, 1408), de 1950, e Sobre as relaçóes entre música e pintura (GS 16, 628-42), de 1965. A distância de quinze anos demonstra a tenacidade da noção de uma "relação conveniente" de cada meio com seu objeto correlato, relação esta que seria assegurada pelo conceito de material, mas que se afastaria da visão sistemática de Lessing. No começo do ensaio de 1950, Adorno sugere que a pseudomorfose da música em direção à pintura, inerente à Aufklärung, caracterizaria a origem de toda música moderna: "Não há dúvida de que as origens da nova música no ocidente podem ser encontradas na pintura." (ADORNO, Sobre a relação entre pintura e música hoje, GS 18, 142). O argumento apoia-se no fato de que as relaçôes entre música e pintura atestam uma contínua e unilateral adaptação histórica da música à pintura, não apenas em certos traços externos, mas em sua especificidade estrutural interna. Após o colapso do figurativo na pintura e da tonalidade na música, tal adaptação coincidiria com a guinada "objetivista" da música moderna em todas suas tendências (incluindo a fase dodecafônica de Schoenberg), confirmando o enfraquecimento do polo subjetivo e a reificação da expressividade musical. Segundo Adorno, a Aufklärung impõe o triunfo do espírito da pintura sobre o espírito da música por sua própria "natureza", a qual privilegia a organizaçáo disciplinada do espaço em detrimento da especificidade caótica, resistente à apreensão conceitual, do tempo; em suma, o triunfo do apolíneo sobre o dionisíaco. A referência à polarização nietzschiana de $O$ nascimento da tragédia entre o caráter apolíneo da pintura e o caráter dionisíaco da música é dada pelo próprio autor (ADORNO, GS 18, 143). ${ }^{16}$

This was undoubtedly as much due to his personal affiliations with composers of the 'Second Viennese School', as any conservative bias toward Austro-German idioms and tradition." (ADLINGTON, 1997, p. 26).

${ }^{16}$ Em $O$ nascimento da tragédia, Nietzsche refere-se à "pintura sonora" (Tonmalerei), como sinônimo de música programática, para indicar a degenerescência da autêntica arte musical. Esta seria 
Fundamentalmente, consideraçóes anteriores de Filosofia da nova música sobre a música de Debussy e Stravinsky reaparecem no ensaio de 1950. Para Adorno, os expedientes modernos da pseudomorfose estariam prefigurados na técnica de Debussy. A obra impressionista, "estática, espacial", não progride, permanece "fora do fluxo temporal." (ADORNO, GS 18, 143). Sua justaposição de complexos sonoros indiferentes à narratividade condicionaria um modo de escuta instantânea, uma organização não progressiva, mas coextensiva: "O decurso temporal não constitui essencialmente a forma, mas corresponde ao ordenamento coextensivo (nebeneinander) e contrastante de superfícies coloridas." (ADORNO, GS 18, 144). O esquema composicional de Debussy recusaria, portanto, a constituição da forma musical, na medida em que esta deveria confrontar dialeticamente a duração mediante o trabalho do desenvolvimento motívico-temático. Conforme Adorno, a sequência dos eventos individuais (die Aufeinanderfolge) em Debussy apresentava-se como fortuita em relação ao "padrão do 'desenvolvimento' (nach dem Maße von 'Entwicklung')" (ADORNO, GS 18, 144). Debussy confirmaria certa submissão modernista da música à pintura, ao organizar essa sequência de maneira coextensiva, cujos eventos sonoros, no limite, seriam permutáveis entre si. Para Adorno, o trabalho motívico-temático e a variação em desenvolvimento constituíam, na prática compositiva, os alicerces da própria subjetividade musical. Assim, uma subjetividade musical ainda se expressaria, em Debussy, como negação determinada à sucessividade do pensamento motívico-temático. Precisamente esse aspecto histórico seria eliminado por Stravinsky.

Adotando o mesmo gesto composicional, Stravinsky permaneceria indiferente à contraposição dialética ao princípio de desenvolvimento que caracterizava a ruptura impressionista, isto é, indiferente às tensóes históricas que a técnica de Debussy provocava no material. Adorno considera que o gesto composicional de Stravinsky coincide com o gesto formal da pintura de Kokoschka. O expressionismo de Kokoschka procuraria dar conta de uma experiência que estaria "genuinamente" (genuin) mais próxima da especificidade musical. Em seu esforço de cristalizar, no meio específico das artes visuais, o fluxo inconsciente

regida pelo princípio dionisíaco de onde se origina a tragédia, posteriormente degenerada em arte da "aparência" que mimetizaria as artes plásticas, guiadas pelo princípio apolíneo de beleza e cingidas pela "consideração teórica" do mundo. A pintura sonora seria, por conseguinte, assim como a ópera do stilo rappresentativo, a negação da verdadeira música. A supremacia da "consideração teórica" sobre a "consideração trágica" do mundo compatibiliza-se com aquela da pseudomorfose da música em pintura, no sentido de uma progressiva dominação do princípio apolíneo (teórico, ordenador, racional) sobre o elemento dionisíaco (trágico e verdadeiramente artístico). (NIETZSCHE, 2007, cap. $16,17)$. 
temporal da experiência, Kokoscha sucumbe inversamente à pseudomorfose da pintura em música. Assim, Stravinsky e Kokoschka cedem, cada qual em relaçáo à especificidade de seus respectivos meios, a pseudomorfoses. Conforme Adorno, Schoenberg e Picasso seriam tecnicamente superiores a Stravinsky e Kokoschka, pois as técnicas daqueles fazem avançar materialmente as particularidades irredutíveis de cada meio, enquanto as técnicas destes cedem a pseudomorfoses. Com Schoenberg, sobretudo no período da atonalidade livre, o material da música avança no princípio de construção diretamente ligado a seu "campo de problemas" (Problemlage) específico; com Picasso, o material da pintura avança na reduçáo às formas puras espaciais, ao esfacelamento em complexos geométricos. É nesse sentido que "tendências formais análogas inevitavelmente possuem significados diferentes, mesmo opostos, na arte temporal da música e na arte espacial da pintura." (ADORNO, GS 18, 142). Ao seguirem as tendências do material da música e da pintura, os procedimentos de Schoenberg e Picasso, ainda que aparentemente "divergentes", constituiriam de maneira homóloga os enclaves de liberdade na arte moderna. Dessa maneira, o conceito dialético de material, vinculado à especificidade de cada meio, atua na deslegitimação adorniana das pseudomorfoses.

Já no ensaio do 1965, Sobre algumas relaçóes entre música e pintura, Adorno desloca o foco da análise para o processo de convergência das artes, relativizando a preponderância dos influxos estruturais da pintura sobre música. Equilibra-se a argumentação mediante o reconhecimento, por exemplo, de permutaçóes que levariam a uma crescente dinamização na evolução da pintura, como a criação da "ilusão temporal". Embora a ideia de "triunfo da pintura sobre a música” do ensaio de 1950 seja atenuada em 1965, Adorno ainda insiste na ideia de espacializaçáo do tempo musical e mesmo na prevalência de tal reversão, quando comparada ao processo de "temporalizaçáo do espaço pictórico": "A música [...] está mais relacionada ao espaço do que a pintura ao tempo." ${ }^{17}$ Logo, a crítica à reificação da subjetividade musical, no interior da qual a pseudomorfose em Stravinsky representaria uma etapa decisiva, é retomada:

Na música, o movimento em direção à pintura, mesmo depois da recusa a Wagner e ao princípio neo-romântico da sinestesia - eu ouço a luz prolongou-se nas correntes antiwagnerianas: uma prova de sua violência subterrânea remanescente. A pseudomorfose em pintura, uma das

${ }_{17}$ ADORNO, Sobre algumas relaçôes entre música e pintura, GS 16, 638: "Indessen ist Musik wahrscheinlich, ihren empirischen Voraussetzungen nach, als innerräumliche sinnfälliger auf den Raum bezogen als Malerei auf die Zeit." 
categorias-chave para Stravinsky, continuação do enfoque de Debussy [...] hoje deve ser compreendida como um degrau no processo de convergência. (ADORNO, Sobre algumas relaçôes entre música e pintura, GS 16, 629). ${ }^{18}$

Assim como no ensaio anterior, a pseudomorfose da música em pintura - "uma das categorias-chave para Stravinsky" - manifesta-se com uma "violência subterrânea”, mesmo naquelas correntes distantes do deliberado projeto wagneriano de espacialização ${ }^{19}$ e de experimentos sinestésicos (como a peça Prometheus, de Alexander Scriabin, de 1910, na qual se utiliza um "teclado de luzes", o Chromola, associando cores a notas).

Rodrigo Duarte defende que o uso da expressão "hoje deve ser compreendida", no trecho acima, sinalizaria uma revisão da postura adorniana quanto à interferência de um meio artístico sobre outro, tendo em vista as manifestações artísticas dos anos 1960; uma revisão que seria posteriormente confirmada, na conferência $A$ arte e as artes (1966). Segundo Duarte, o conceito de pseudomorfose refere-se inicialmente a um dos momentos centrais da crítica adorniana à reificação dos meios: "O aspecto essencialmente crítico que o conceito assume em Adorno diz respeito ao fato de que metamorfose é o indício de um estado de coisas alienado, reificado." (DUARTE, 2009, p. 35). Náo obstante, Duarte defende que, em meados dos anos 1960, Adorno passaria a legitimar certa modalidade de importação de procedimentos de um meio artístico para outro, a possibilidade de uma "inter-relação autêntica dos diversos métiers", inter-relação esta que, "no contexto da arte contemporânea, pode ser importante e até mesmo desejável.” (DUARTE, 2009, p. 39). Para Duarte, tal reavaliação do conceito de pseudomorfose, efetuada "sob pressão de importantes acontecimentos dos anos 1960", estaria plenamente consubstanciada na conferência de 1966, quando se examinava o fenômeno da "imbricação" (Verfransung) (DUARTE, 2009, p. 40). Em linha interpretativa semelhante, Borio defende que "Adorno reconsiderou o problema da pseudomorfose" no ensaio sobre música e pintura de 1965, de sorte que o mesmo fenômeno que ele "discerniu em Debussy e Stravinsky foi reinterpretado como o prenúncio de um processo de convergência entre formas de representação artística, que tanto se referia a procedimentos estruturais quanto a princípios estéticos.”

\footnotetext{
${ }^{18}$ Tradução em Duarte (2009, p. 40).

${ }^{19}$ No Ensaio sobre Wagner, Adorno defendia a ideia de uma espacialização do tempo no drama musical de Wagner, concretizada na declaraçáo do personagem Gurnemanz no primeiro ato de Parsifal: "Aqui o tempo vira espaço [Gurnemanz: Du sieh'st, mein Sohn, zum Raum wird hier die Zeit.]." (ADORNO, Ensaio sobre Wagner, GS 13, 85).
} 
(BORIO, 2006, p. 66). Borio acredita que a ideia de pseudomorfose, "um dos momentos mais virtuosos da crítica a Stravinsky em Filosofia da nova música", seria "agora tratada positivamente." (BORIO, 2006, p. 65).

No entanto, tendo em vista a estrita continuidade entre os textos de Adorno, notamos que o filósofo não abandonou sua crítica à pseudomorfose, tampouco reconsiderou o tratamento dessa noção em termos positivos. De fato, a pseudomorfose permanece uma das figuras centrais da Aufklärung musical, ao longo de toda a reflexão de Adorno até Teoria Estética. O que Adorno parece antes visar, na década de 1960, seria a exposição das razóes que levariam a uma intensificação de um processo análogo à pseudomorfose em direção à convergência dos meios. Adorno pretendia compreender a situação histórica que indicava certa exaustão do processo de autonomização. No ensaio de 1965, o ideal do desenvolvimento motívico-temático, mencionado não sem um acento nostálgico, ainda é considerado imprescindível à forma musical:

Aquilo que na música tradicional, incluindo Schoenberg, Berg e Webern, vale especificamente para a dimensão temporal - toda a arte do desenvolvimento e da transição temática [die gesamte Kunst von Entwicklung und thematische Übergang] - torna-se irrelevante para os compositores [de hoje]. (ADORNO, Sobre algumas relações entre música e pintura, GS 16, 630, grifo nosso).

Ou seja, mesmo em 1965, quando o problema da convergência dos meios passa a ser diretamente tematizado por Adorno, aquilo que "vale especificamente para a dimensão temporal”, aquilo que está baseado na relação diastêmica entre notas, constitui a essência dialética do trabalho composicional. Ao contrário da interpretação de Duarte e Borio, acreditamos que o enfrentamento do problema da convergência não conduz a reavaliaçóes sobre $o$ conceito de pseudomorfose. A estranha alusão, no trecho acima, a compositores da Segunda Escola de Viena como pertencentes à "música tradicional" não deveria nos iludir quanto à adesão tardia e melancólica a técnicas que já estariam obsoletas, em 1965. O que antes ficaria confirmado é o diagnóstico de retração da subjetividade na nova música "não-tradicional", cujo processo de espacialização oblitera a essência dialética de "toda arte da Entwicklung" musical, isto é, do pensamento motívico-temático.

Ainda no ensaio sobre música e pintura de 1965, Adorno indicava três momentos históricos decisivos do processo de pseudomorfose, simbolizados respectivamente pelas obras de Debussy, Stravinsky, Stockhausen. Debussy 
dissolve, com a técnica impressionista, o material motívico-temático em "partículas" a serem arranjadas por justaposição; Stravinsky trata o próprio tempo "como se" fosse espaço, mediante a incipiente composição por blocos sonoros; por fim, de maneira ainda mais radical do que em Stravinsky, o pontilhismo da primeira fase de Stockhausen recusaria de saída a ideia de sucessividade, a tal ponto que, se, em Stravinsky, a sucessão ainda era submetida a uma fragmentação de forma coextensiva (nebeneinander), na qual o tempo era tratado alusivamente "como se" fosse espaço, em Stockhausen, a sucessão seria totalmente "planejada, disposta do alto como uma superfície visual." (ADORNO, GS 16, 630).

Vale a pena detalharmos esse último momento do processo de pseudomorfose. O que Adorno sugere é que o antigo "como se" da pseudomorfose em Stravinsky - equivalente a uma recusa performática e ainda não "autorizada” pelo estágio histórico do material, no início do século 20 - teria sido completamente eliminado nos anos 1950, para se tornar um simples como: Stockhausen trata o tempo como espaço. Esse diagnóstico já estava presente no ensaio Música e nova música (1960), no qual Adorno constatava que "a organização do tempo como espaço agora se torna uma preocupação séria: o próprio tempo deve, pela manipulação serial, tornar-se disponível e, em alguma medida, ser capturado" - uma organização que, em Stravinsky, ainda se manifestava por meio de um "como se", de um "sonho do que estaria por vir". ${ }^{20}$

O tratamento por blocos, baseado na completa homofonia, na atomização da nota individual ou de clusters, ignorando a relação entre notas, manipula o tempo como se este fosse uma "caixa" (Karton $)^{21}$, não encontrando correspondente na pseudomorfose da pintura em música, em termos de dinamização. Assim, a radicalidade e a aporia da espacialização, na música contemporânea, decorrem da transformaçáo do próprio meio temporal em material, da absoluta identidade do tempo com espaço (ADORNO, GS 16, 631). É a partir desse diagnóstico, inclusive, que o tom programático do ensaio de Adorno Vers une musique informelle (1961) incitava a busca por modelos com-

\footnotetext{
${ }^{20}$ Adorno, Música e nova música, GS 16, 484: "Was bei Strawinsky, vielleicht als verstörter Traum eines Kommenden, noch Als ob blieb, die Zurichtung der Zeit, als wäre sie Raum, wird ernst: Zeit selber soll, durch serielle Manipulation, disponibel, gewissermaßen eingefangen werden. Offen nicht länger, scheint sie verräumlicht."

${ }^{21}$ Adorno, Sobre algumas relaçöes entre música e pintura, GS 16, 630: "Zeit wird nicht zu einem geometrischen Nebeneinander verräumlicht, aber insgesamt, gerade als Zeit, geplant, disponiert, von oben her organisiert wie einst nur visuelle Flächen. Der disponierenden, die Zeit wie einen Karton behandelnden Verhaltensweise im Großen entspricht eine nicht minder malerische im Kleinen.”
} 
posicionais capazes de recuperar o gesto expressivo dos anos 1910, época de ruptura com a tonalidade; de acordo com Adorno, esse gesto radical teria sido esquecido pelos novos compositores dos anos 1950.

Notemos que Adorno queria evitar precisamente os perigos de toda pseudomorfose: "Para que a música se liberte da pseudomorfose stravinskyana em pintura, é necessária uma reforma do próprio compor" ${ }^{22}$, defendia, em 1961. Se, para o ensaio de 1965, a pseudomorfose constitui uma etapa decisiva do processo de convergência entre os meios artísticos na contemporaneidade, é porque, longe de revisionismos entre a posição de 1950 e a de 1965, a figura da pseudomorfose expóe agora com maior clareza o momento de regressáo subjacente a uma das faces dialéticas do conceito de convergência entre os meios, no plano mais abrangente da Aufklärung.

O conceito de "princípio imanente" ligado ao material ocupa um lugar estratégico na argumentação adorniana e reforça, a nosso ver, a continuidade entre os dois ensaios. Se, para o ensaio de 1950, as obras de Schoenberg e Picasso, em razão do avanço técnico de seus materiais específicos, representavam um estágio de liberdade no desenvolvimento dos respectivos princípios imanentes (a faticidade temporal na música e a faticidade espacial na pintura, de acordo com a irredutibilidade de cada meio), para o ensaio de 1965, esses desdobramentos, essencialmente antípodas entre si, são o que paradoxalmente asseguram sua convergência. Para o ensaio de 1965, as artes não convergem nem por sinestesia, nem por semelhança (Anähnelung) nem por pseudomorfose, contudo, convergem em um "terceiro": em seu caráter de linguagem, que implica tanto a écriture e a construção imanente em cada meio, quanto a repulsa a modelos comunicativos de expressividade. Ambas se encontram em algo "espiritual", na linguagem do não-subjetivo que rompe as estratégias transcendentais de uma síntese do eu (ADORNO, GS 16, 635).

Assim, podemos sustentar que o ensaio de 1965 esclarece, de maneira retroativa, os motivos pelos quais, para Adorno, em 1950, Schoenberg e Picasso também já convergiam em sua plena divergência de procedimentos: Schoenberg, guiado pela expansão do momento subjetivo na atonalidade livre (faticidade temporal); Picasso, guiado pela contração objetiva a elementos geométricos no cubismo (faticidade espacial). Como a convergência se localiza na partilha reflexiva do mesmo "núcleo da experiência histórica", expressando seu teor de verdade, é nesse sentido que "os extremos se

22 Adorno, Vers une musique informelle, GS 16, 533: "Daß die Musik aus der Strawinskyschen Pseudomorphose an die Malerei sich befreie, erheischt Umformung des Komponierten selbst.” 
tocam" (ADORNO, Sobre a relação entre música e pintura, GS 18, 147). Ao mobilizar os conceitos de écriture e construção, o ensaio de 1965 traz a ideia de convergência (Konvergenz), certamente embrionária em 1950, elaborada como o resultado da espiritualização (Geistigung) dos materiais específicos, mas não ainda como a fusão de meios artísticos. A convergência, portanto, não é nem a pseudomorfose nem a fusão entre os meios. E isso estaria assegurado pelo conceito de écriture, outro nome para construção: "o conceito de construção, que encoraja a convergência, torna-se cada vez mais poderoso à medida que as artes se encontram cada vez mais confrontadas diretamente com o material nu com o qual trabalham.” (ADORNO, GS 16, 641). Quanto maior o teor da reflexividade técnica de uma obra sobre as especificidades imanentes a seu meio, mais acentuada será a convergência com obras de outros meios que mantenham o mesmo teor.

Refuta-se, com isso, toda espécie de sinestesia ou de sincretismo, de "contínuo não dialético das artes em geral", que caracterizam aqueles experimentos artísticos dispostos a reanimar o preceito da "obra de arte total". Isso significa que o movimento dialético do material não se dá pelo cruzamento entre os meios, mas é ocasionado pelas tensôes históricas e monadológicas, as quais se dão no interior do próprio meio. Sob esse aspecto, Adorno retoma sua crítica à aparência de totalidade da Gesamtkunstwerk de Wagner, posteriormente retomada pelos experimentos vanguardistas. Já no Ensaio sobre Wagner, no final dos anos 1930, Adorno qualificava o conceito de "obra de arte total" de "diletante", pois envolvia a fusão entre os meios. O projeto wagneriano, em sua propensão à fantasmagoria, visava dissimular a autonomização dos diferentes meios, através de uma convergência náo dialética. O problema da obra de arte total reside, portanto, na disposição superficial de uma fusão técnica arbitrária dos meios, sem que seus materiais o exijam historicamente. ${ }^{23}$

Esse comentário do final dos anos 1930 repercute nos conceitos de convergência e imbricação (Verfransung). Temos boas razões para acreditar que o ensaio de 1965 não altera o posicionamento teórico de Adorno em relação à ideia de convergência: apenas modula seu significado para o novo contexto

\footnotetext{
${ }^{23}$ É nesse sentido que Adorno subscrevia, no Ensaio sobre Wagner, o comentário de Thomas Mann sobre o "diletantismo" da ideia de obra de arte total: "Pode-se dizer, sob risco de ser mal compreendido, que a arte de Wagner é produto do diletantismo, ainda que monumentalizado pelas mais altas forças da vontade e da inteligência, elevado ao nível da genialidade. A ideia de unificação de todas as artes é ela própria diletante e, na falta do esforço supremo de sujeita-las a seu gênio expressivo, teria permanecido como tal. Sua relação com as artes permanece duvidosa; por mais estranho que pareça, há nela algo de amusia [Amusisches]." (MANN apud ADORNO, Ensaio sobre Wagner, GS 13, 26-7).
} 
da "imbricação" dos anos 1960. Convergência e imbricação legitimam-se, por conseguinte, não pela inversão diletante de procedimentos, por pseudomorfoses, mas pelo resultado de uma experiência histórica partilhada no caráter de linguagem, no encontro dialético do material com a "essência" de seu meio. Em resumo, até podemos admitir como válida a crítica à postura essencialista de Adorno, quanto à determinação da especificidade "incondicional" de cada meio (temporalidade na música, espacialidade na pintura), consequência de uma separação racional que retoma, com efeito, a divisão de Lessing. Contudo, é forçoso reconhecer uma estrita continuidade entre o que Adorno defendia no final dos anos 1930 e o que defendia nos anos 1960. Com isso, afastaríamos qualquer hipótese de revisionismos.

\section{O FANTASMa IDEALISTA DE Lessing}

Todavia, é forçoso também fazer um recuo. Com os conceitos de convergência, em 1965, e de imbricação, em 1966, Adorno não compreendia a síntese das artes como a tendência necessariamente progressista das vanguardas do período. Denunciava inclusive o risco de declínio irracionalista e de regressão a estágios primitivos, anteriores à própria segmentação dos meios artísticos. Por um lado, Adorno concebia tanto a dissolução das fronteiras entre os meios quanto a convergência como processos irrefreáveis da Aufklärung. Por outro, apontava para os riscos de "crasso infantilismo" (ADORNO, GS 16, 631) nesse percurso, lembrando que, na contemporaneidade, os progressos técnicos mais extremos se entrelaçam a um momento de regressão ao impulso mimético puro, anterior à própria separação racional dos meios (ADORNO, GS 16, 642). O ensaio de 1965 termina, na realidade, com duas perspectivas extremamente céticas: a arte de vanguarda cederia ou a um retorno dialético de dominaçáo sobre esse elemento regressivo que tenta promover a fusão pré-racional dos meios ou à queda a uma "literalidade bárbara" (barbarischen Buchstäblichkeit), o culto a um material absoluto.

De todo modo, convém perceber o quanto a posição teórica nos dois ensaios é tributária à doutrina e à terminologia de Lessing, sobretudo quando se refere ao conceito de pseudomorfose. A ênfase no "triunfo da pintura sobre música”, no ensaio de 1950, e a reavaliação que indica certo equilíbrio nessa relação, no ensaio de 1965, não escondem a profunda convicção de Adorno de que a categoria de autonomia estética só se realiza em procedimentos adequados à especificidade de cada meio, que estabelece um campo particular de problemas 
- uma convicção que seria tautológica só à primeira vista. Assim, a redução da pintura à essência da espacialidade da tela - a emancipação das formas geométricas e da cor em relação a todo referente pictórico, a bidimensionalidade - resulta do desenvolvimento autônomo do material nas artes visuais. Lembremos que, para Lessing, a pintura não deveria ser temporal, pois essa dimensão não é própria a seus objetos nem à natureza essencial de seu meio; a pintura deve capturar o momento fecundo. $\mathrm{Na}$ medida em que o tempo náo pode ser representado diretamente (apenas alusivamente) pelo meio visual, seus signos devem ser agenciados de maneira coextensiva, ordenados ao lado do outro.

Como Adorno observa, a divisão sistemática de Lessing atende às exigências prescritivas do classicismo, comportando um momento ideológico e interesses de ocasião (como vimos, na citação acima de Suzuki, sobre o interesse de Lessing pelo teatro). Para sermos mais claros: Adorno náo aceita o ideal normativo das categorias universais de Lessing. Contudo, sua compreensão de certos fenômenos contemporâneos na música e na pintura acabaria atualizando a ideia de incondicionado que define estruturalmente cada meio, um incondicionado que prescreve "leis imanentes", o que evoca a contrapelo aquela divisão de Lessing. Isso se manifesta com maior evidência, quando Adorno se refere às "condiçóes de possibilidade da arte temporal", às "invariantes" do meio da sucessão como um abstrato a priori, ao compromisso com a articulação do decurso temporal ou, ainda, quando insiste no desenvolvimento de um "campo de problemas" particular - e sabemos que tal insistência ocorre não somente nos ensaios sobre música e pintura. É preciso reconhecer que Adorno defende também a imanência da dimensão temporal, na pintura, como sedimentação das tensôes na construção da tela - "o tempo é imanente à pintura" ${ }^{24}$; da mesma forma, reitera que a dimensão espacial pertence à música - "o espaço é condição para objetivação da música”. ${ }^{25}$ Acontece que, talvez para a surpresa do materialismo de Adorno, essa era exatamente a mesma posição da doutrina idealista de Lessing, já que, para ele, o tempo na pintura, assim como o espaço na música, aparecem, mesmo de "maneira alusiva". Além disso, a recorrência nos ensaios de Adorno de termos como arte do es-

\footnotetext{
${ }^{24}$ ADORNO, Sobre algumas relaçōes entre música e pintura, GS 16, 632: "Darum ist Zeit, jenseits der bei seiner Herstellung aufgewandten, dem Bild immanent."

${ }^{25}$ A dimensão espacial estaria consubstanciada não apenas na ideia de "forma" e "construçâo", mas também na possibilidade de refutar o decreto da natureza antropológica dos sentidos. "Wehrt sich, mit allem Grund, die Tendenz zur Verräumlichung der Musik wider das Dekret, das auf Invarianten der anthropologischen Beschaffenheit der Sinne pocht, darauf, daß Auge Auge, Ohr Ohr bleibe, so darf sie darum nicht identitätswütig ihr Anderes verkennen." (ADORNO, Sobre algumas relaçôes entre música e pintura, GS 16, 631).
} 
paço (Raumkunst) e arte do tempo (Zeitkunst), a distinção entre a organização coextensiva (nebeneinander) e a organização sucessiva (aufeinanderfolgende), o apelo a asserções tautológicas que reclamariam a organização essencial da sucessividade na música e uma verdadeira intervenção subjetiva proveniente do impulso temporal, tudo isso sugere uma proximidade por demais evidente com o programa clássico de Lessing. ${ }^{26}$

Acreditamos que a escolha da linguagem da pintura não serve apenas de contraponto dialético, de polo necessário, à compreensão da "essência temporal" da música. Notemos que Adorno não publicou ensaios, por exemplo, sobre as relaçôes entre música e literatura, ainda que música e literatura separadamente constituíssem o núcleo de seus interesses filosóficos sobre arte. A arte do espaço serve de contraponto conveniente para sua teoria dos extremos, na medida em que o tempo, em termos hegelianos, é, primeiramente, "a negação da indiferença recíproca que define o modo de ser da espacialidade" (ARANTES, 2000, p. 55). Entretanto, mais do que isso, a função decisiva que impulsiona a reincidência do tema sobre artes do tempo e artes do espaço, quinze anos após a publicaçáo do primeiro ensaio, diz respeito à rejeição de uma síntese não-dialética das artes no contexto dos debates dos anos 1960, quando se torna mais evidente o esfacelamento das fronteiras entre os diversos meios artísticos. Tal rejeição ficaria mais bem delineada no ensaio de 1967, A arte e as artes, sobre o qual comentaremos, a título de conclusão.

\section{CONCLUSÃ̃o: CONVERGÊNCIA, IMBRICAÇÃo E A REJEIÇÃo DE UMA SÍNTESE SISTEMÁTICA DAS ARTES}

$A$ arte e as artes, ${ }^{27}$ publicado em 1967, resulta da palestra proferida por Adorno, em 1966, na Akademie der Künste de Berlim, portanto, apenas um ano depois da publicação do segundo ensaio sobre música e pintura. Nessa conferência, Adorno procura detalhar sua interpretação sobre o fenômeno da erosão das fronteiras tradicionais das artes, tendo em vista a frequência daquilo que denominava "processos de imbricação" (Verfransungsprozess), em exemplos contemporâneos significativos da música, da literatura, das artes visuais, além da emergência de novos "gêneros", como o happening. Nossa hipótese é a de

\footnotetext{
${ }^{26}$ Adorno, Ibid., GS 16, 631: "Durch die Organisation der Zeit Organisierte (ist) nicht gleichzeitig, sondern sukzessiv; der Sachverhalt läßt anders als tautologisch gar nicht sich aussprechen.”

${ }^{27}$ Adorno, Die Kunst und die Künste, GS 10.1, 432-453.
} 
que Adorno procura compatibilizar a noção de imbricação com o conceito de convergência, defendido no ensaio anterior, de 1965, sobre música e pintura.

$\mathrm{O}$ texto $A$ arte $e$ as artes consiste, primeiramente, em um diagnóstico de época, assinalando exemplos notórios de imbricação (em artistas como Bussotti, Helms, Schultze, Calder, Wotruba) e os antecedentes do processo de convergência. Em seguida, discute as insuficiências de representantes da estética moderna, como Hegel, Schopenhauer e Kandinsky, que propuseram sistemas para a compreensão da síntese teórica dos meios, seja pelo estabelecimento de paragone (no qual um meio deveria "guiar" os demais), seja pela sua fusão abstrata "simbiótica" (Kandinsky); expõe criticamente então as estratégias básicas de duas ontologias de arte contemporâneas - Borchadt e Heidegger, os quais, de modo náo dialético, priorizam um conceito genérico de arte ou de pluralidade das artes; finalmente, encaminha um conceito negativo de arte, coadunando-se à problemática da perda de sentido decorrente do nominalismo estético. Para o propósito do nosso artigo, interessa-nos a última parte do ensaio, na qual após reconhecer a modificação da constelaçáo dos meios na arte contemporânea, que envolvia a mudança estrutural de procedimentos, o surgimento de gêneros como happening (como "obra de antiarte total"), e mesmo uma reavaliaçáo do lugar social do cinema - Adorno reitera a primazia do conceito de material. $\mathrm{O}$ aparente paradoxo da reflexão adorniana estaria em, por um lado, denunciar o caráter postiço de toda teoria que define de modo transcendental a especificidade de cada meio e, por outro, conservar tanto o conceito modernista de autonomia quanto a própria especificidade de cada meio.

Para dissolvermos o paradoxo, sublinhemos novamente a razão pela qual Adorno preserva a delimitação das fronteiras dos meios em sua irredutibilidade, mesmo quando reconhece o conceito de convergência e o fenômeno de imbricação. A fim de rejeitar a redução qualitativa de fenômenos artísticos a um termo geral (as artes não formam um continuum), Adorno não abre mão de "diferenças essenciais" historicamente consolidadas dos meios, uma separação racional dos meios, seja entre artes "baseadas em imagens, imitativas, representacionais" e aquelas "originalmente despojadas das imagens", ou ainda, entre artes "conceituais" e "não-conceituais" (ADORNO, $A$ arte e as artes, GS 10.1, 447). Os significados de tais categorizaçôes são continuamente tensionados pelas obras individuais, mas elas decorrem post facto, e somente uma visão retrospectiva do conjunto poderia inscrever tais diferenças em uma ontologia de arte acabada. De toda forma, uma vez emancipadas e racionalizadas, essas diferenças estabelecem certas "invariantes", leis e "princípios ima- 
nentes" de desenvolvimento. A irredutibilidade, marcada pela recusa tanto de uma categoria transcendental, que realizaria "do alto" a partilha sensorial em meios particulares específicos, quanto de uma ideia ulterior de síntese, permite compreender a erosão das artes e o conceito de imbricação sob outra perspectiva. O rigor dialético pela delimitação dos meios, que, não custa insistir, se preserva na filosofia adorniana mesmo tardiamente, em 1966, remete assim a seu conceito de material.

Como vimos, o material, enquanto mediação histórica e parte integrante do processo de dominação da natureza, difere radicalmente da "matéria". No caso da música, a organização dos sons, cuja produção e recepção são historicamente determinadas, se distingue da ideia de som imediato, da matéria em estado "puro", "natural"; no caso da pintura, do mesmo modo, a produção e a recepção historicamente determinadas da materialidade da linha ou da cor diferem de tais elementos tomados em estado "puro", em sentido não-histórico. Para Adorno, a própria ideia de uma "matéria supostamente bruta" integra-se à "dialética da espiritualização" do material. A emancipação do ruído em John Cage, por exemplo, o qual procurava eliminar por "decreto estético" toda historicidade do som, sempre possui inevitavelmente um núcleo histórico e social, assim como a "espontaneidade" do action painting de Pollock ou Kline sempre possui um núcleo histórico e social. A forma estética só atinge seu teor de verdade quando resulta de uma exigência interna do material conferida por esse núcleo. A autêntica convergência entre as artes, portanto, resulta de uma exigência dos próprios materiais, da articulaçáo interna de cada meio, que se materializa na obra singularizada. É nesse sentido que uma "estética da obra" (e não de um estilo), comprometida em "resolver" problemas ou explorar as possibilidades das obras anteriores, fornecidas pelo próprio meio de maneira determinada, conduz à recusa adorniana de uma síntese ou sistematizaçâo das artes. A imbricação, que dilui as fronteiras tradicionais dos meios, é assim impulsionada pela própria categoria de autonomia dos meios, como negação determinada intraestética respectiva.

Em Teoria estética, ao se contrapor à fetichização da categoria de novo, à sua transformação em categoria abstrata, Adorno declarava que, "quando a possibilidade de inovação se esgota, a tendência da inovação deve mudar e ser buscada em outra dimensão" (ADORNO, GS 7, 41). Essa busca em outra "dimensão", determinada internamente pelo material de cada meio, é o que melhor caracteriza a noção de imbricação. Em suma, o processo a que Adorno se refere não corresponde à "intersemiose", a uma convergência no sentido da 
construção de "intermeios”, tampouco a "multimeios” artísticos; a imbricação aqui significaria uma espécie de concórdia na écriture dos diferentes meios dado pelo momento histórico, sua transformação em "parameios" ${ }^{28}$

Anne Boissière sugere que os conceitos de convergência e imbricação começam a ser engendrados por Adorno, quando um nominalismo estético passa a prevalecer no cenário da arte contemporânea (BOISSIÈRE, 1999, p. 181). Por nominalismo, Adorno compreenderia a emancipação estrutural de esquemas herdados da tradição, o afastamento radical de toda convenção. Consequentemente, tal individualização extrema da forma em certas obras contemporâneas conduzia à perda do referente da alteridade. No momento em que uma obra estabelece uma rede de relaçóes de seus elementos internos sem remissáo a formas anteriores, ela acaba perdendo a história sedimentada do material. Assim, a questão da diferença entre as artes individuais se torna uma questáo, para Adorno, apenas nesse momento em que a emancipação histórica do conceito de forma se concretiza por uma exigência interna dos materiais, nesse momento em que os gêneros que antes abrigavam o estoque de modelos formais começam a estiolar em sua exigência resoluta pelo novo.

Não se trata, portanto, de pseudomorfose. A imitação das artes entre si mediante um princípio externo - como a pseudomorfose em Stravinsky - designava uma falsa convergência, por ignorar não apenas a especificidade, mas também a historicidade do meio. Já a imbricação entre as artes individuais resultaria de uma conquista do alargamento reflexivo do material, no interior formal das obras. Ou seja, quando as obras, seguindo as "leis imanentes", se encaminham ao nominalismo e atingem uma situação extrema, na qual as fronteiras entre meios tendem a desvanecer - fenômeno que diverge, vale a pena insistir, da revogação arbitrária, implícita na ideia de "síntese das artes". É nesse sentido que o conceito de material justifica tanto a exigência dialética de uma diferença dos meios quanto os processos de convergência e imbricação posteriores. Nesse ponto, a atitude teórica de Adorno remete àquela da doutrina de Lessing.

SOCHA, E. Lessing and Adorno's aesthetics: music, painting, and the problem of pseudomorphosis. Trans/form/açāo, Marília, v. 42, n. 3, p. 91-118, Jul./Set., 2019.

${ }^{28}$ Devo ao professor Ricardo Fabbrini a sugestấo do termo "parameios" e o comentário sobre essa oposição de Adorno a uma tradução intersemiótica entre os meios. 
ABSTRACTs: This article presents a comparison of Gotthold E. Lessing's theory of signs, as found in his Laocoön: an essay on the limits of painting and poetry (1766), and Theodore W. Adorno's two essays on the relationship between music and painting. Our aim is to point out the decisive influence of German classical aesthetics on Adorno's post-war aesthetics. Specifically, we discuss how Lessing's theory functions as a framework for Adorno's dialectical assessment of the formal specificity of artistic media and their possibilities of convergence in the context of the 1960's avant-garde. In this context, we discuss the main implications of Adorno's famous lecture of 1966, Art and the arts, which concerned the process of media convergence (Konvergenz) that intensified during the 1960's, as well as the concepts of "overlapping" (Verfransung) between artistic media and of "pseudomorphosis".

KeYwords: Lessing. Adorno. Music. Painting. Pseudomorphosis.

\section{REFERÊNCIAS}

ADORNO, T. W. Gesammelte Schriften in 20 Bänden. Frankfurt am Main:

Suhrkamp, 1986. (edição citada como GS, seguido do número do volume e da página correspondente).

ADLINGTON, R. Musical temporality: perspectives from Adorno and de Man. Repercussions, v. 6, n. 1, p. 5-60, 1997.

ARANTES, P. E. Hegel: a ordem do tempo. São Paulo: Hucitec/Polis, 2000.

BOISSIÈRE, A. Adorno: la vérité de la musique moderne. Villeneuve d'Ascq: Presses Universitaire Septentrion, 1999.

2011.

. La pensée musicale de Theodor W. Adorno: l'épique et le temps. Paris: Beauchesne,

BORIO, G. "Dire cela, sans savoir quoi" : the question of meaning in Adorno and in the musical avantgarde. In: HOECKNER, B. (ed.). Apparitions: new perspectives on Adorno and Twentieth Century Music. New York: Routledge, 2006.

BÜRGER, P. Zur Kritik der idealistischen Ästhetik. Frankfurt a. M.: Suhrkamp, 1983.

Teoria da vanguarda. Tradução de José Pedro Antunes. São Paulo: Cosac Naify, 2008.

CHUA, D. K. L. Rioting with Stravinsky: a particular analysis of the Rite of Spring. Music Analysis, v. 26, n. 1-2, p. 59-109, mar. 2007.

DAHLHAUS, C. Das Problem der "höheren Kritik": Adornos Polemik gegen Strawinsky. Neue Zeitschrift fur Musik, n. 148/5, 1987.

DUARTE, R. Sobre o conceito de "pseudomorfose" em Theodor Adorno. Artefilosofia, n. 7, p. 31-40, 2009.

HANSEN, J. A. Categorias epidíticas da ekphrasis. Revista USP, n. 71, p. 85-105, 2006.

KLEIN, R. Die Frage nach der Musikalischen Zeit. In: Adorno-Handbuch: Leben - Werk Wirkung. Stuttgart: Metzler, 2011. p. 59-74. 
LESSING, G. E. Laocoonte ou sobre as fronteiras da pintura e da poesia: com esclarecimentos ocasionais sobre diferentes pontos da história da arte antiga. Tradução de Márcio Seligmann-Silva. São Paulo: Iluminuras, 1998.

MITCHELL, W. J. T. The politics of genre: space and time in Lessing's Laocoon. Representations, n. 6, p. 98-115, Spring, 1984.

NIETZSCHE, F. W. O nascimento da tragédia ou helenismo e pessimismo. Traduçáo de Jacó Guinsburg. São Paulo: Companhia de Bolso, 2007.

RICHTER, S. Intimate relations: music in and around Lessing's "Laokoon". Poetics Today, v. 20, n. 2, p. 155-173, 1999.

SUZUKI, M. A tragédia e a verdade de Laocoonte. In: Filosofia e literatura: o trágico. Rio de Janeiro: Jorge Zahar, 2001.

TODOROV, T. Poiética e poética segundo Lessing. In: Os gêneros do discurso. São Paulo: Martins Fontes, 1980.

ZAGORSKI, M. "Nach dem Weltuntergang”: Adorno's Engagement with Postwar Music. Journal of Musicology, v. 22, n. 4, p. 680-701, out. 2005. 